\title{
REFERENCE THORIUM FUEL CYCLE
}

F. E. Driggers

September 1977

Approved by

L. H. Meyer, Program Manager

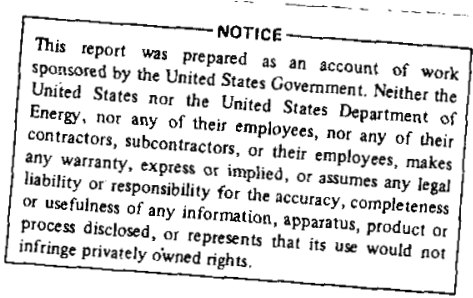

E. I. DU PONT DE NEMOURS AND COMPANY SAVANNAH RIVER LABORATORY

AIKEN, SOUTH CAROLINA 29801

PREPARED FOR THE U. S. ENERGY RESEARCH AND DEVELOPMENT ADMINISTRATION UNDER CONTRACT AT(07-21-1 


\section{DISCLAIMER}

This report was prepared as an account of work sponsored by an agency of the United States Government. Neither the United States Government nor any agency Thereof, nor any of their employees, makes any warranty, express or implied, or assumes any legal liability or responsibility for the accuracy, completeness, or usefulness of any information, apparatus, product, or process disclosed, or represents that its use would not infringe privately owned rights. Reference herein to any specific commercial product, process, or service by trade name, trademark, manufacturer, or otherwise does not necessarily constitute or imply its endorsement, recommendation, or favoring by the United States Government or any agency thereof. The views and opinions of authors expressed herein do not necessarily state or reflect those of the United States Government or any agency thereof. 


\section{DISCLAIMER}

Portions of this document may be illegible in electronic image products. Images are produced from the best available original document. 
REFERENCE THORIUM FUEL CYCLE

\section{INTRODUCTION}

Development of processing technology for spent thorium fuel is scheduled to begin October 1,1977 as part of the Thorium Fue1 Cycle Technology Program (TFCT Program). The scope of the program includes broad evaluations to identify viable thorium/uranium recycle strategies; research and development programs to confirm the feasibility of the selected fuel cycle or cycles; a design integration study to identify development areas and safeguards and proliferation aspects; and the development and testing of key systems, equipment, and components.

The purpose of this report is to define a preliminary thorium fuel cycle to serve as a common basis for beginning development work on October 1, 1977, at participating ERDA Laboratories, universities, and commercial facilities. A final selection of a reference fuel cycle will depend on an evaluation of proliferation resistance and environmental effects and on an economic evaluation of the total system including RGD costs, resource costs, and capital and operating costs for commercializing the total fuel cycle. The fuel cycle described in this report should be considered preliminary because discussions are not yet complete with those organizations responsible for the reactor fuel design and fabrication, because proliferation criteria have not yet been completely developed, and because economic comparisons of alternative thorium fuel cycles are not complete. The fuel cycle described in this report was selected primarily from the point of view of the ease of aqueous chemical processing.

\section{SUMMARY}

Characteristics of the reference fuel cycle for the TFCT Program are:

- Fissile uranium will be denatured by mixing with ${ }^{238} \mathrm{U}$.

- Chemical processing plant design will be based on the assumption that plants are located in secure areas.

- Plutonium will be recycled within these secure areas.

- Thorium will be recycled with recovered uranium and plutonium. 
- The head end of the chemical processing plant will handle a variety of core and blanket fuel assembly designs for light water reactors (LWRs) and heavy water reactors (HWRs).

- The fuel form will be a homogeneous mixture of uranium and thorium oxide powders pressed into pellets.

- Fuel cladding will be Zirealoy.*

- Mg0 will be added to the fuel to improve the thorium dissolving characteristics.

Thorium is being considered as the fertile component of nuclear reactor fuel in the expectation that its use will provide increased proliferation resistance compared to the use of ${ }^{238} \mathrm{U}$ as the fertile material in reactor fuel. The reason is that ${ }^{235} \mathrm{U}$ (which constitutes the initial fissile content) and ${ }^{233} \mathrm{U}$ (which is produced when thorium is irradiated) can be denatured, or made unusable for feasible explosive devices, by mixing with ${ }^{238} \mathrm{U}$, whereas plutonium cannot be denatured. However, the use of ${ }^{238} \mathrm{U}$ results in the production of plutonium during irradiation at a rate of about one-third that in LWR uranium fuel cycles. It is thought that a reprocessing plant cannot be designed to prevent the recovery of this plutonium by those in control of a functioning plant, and it is therefore assumed that the plant will be located in a secure area. Within this area, it is assumed that plutonium can be fabricated into fuel assemblies in co-located facilities and recycled in co-located reactors. It is also assumed that spent uranium can be processed if it is economically attractive to do so. A block diagram of the proposed fuel cycle is included (Figure 2).

Spent uranium must be re-enriched prior to recycle in a reactor. It is assumed that this will be done by blending with highly enriched uranium. Use of highly enriched uranium $(50 \%$ $93 \%{ }^{2}{ }^{5} \mathrm{U}$ ) results in decreased use of $238 \mathrm{U}$ and in decreased uranium feed and separative work requirements.

Alternatives to some of the selected fuel characteristics will be considered during early stages of the program. The dates by which preliminary selections must be made are obtained by working back from the date on which preliminary technical data summaries are required for the design integration studies. Results from subsequent R\&्षD efforts may dictate later changes in these selections.

* Registered trademark of Westinghouse Electric Corp., Blairsville, Pa. 
Choice

Pressed powder or compacted microspheres

Zircaloy or stainless steel cladding

Use of additives

Thorium - recycle or stowaway
Decision Date

January $1978 \leftarrow$

April 1978

Apri 11978

June 1978

\section{DETAILS}

\section{Proliferation Resistance}

Proliferation criteria have not yet been completely established, hence, some assumptions have been made concerning these criteria. It is understood that the selected fuel cycle may require some modifications when proliferation criteria are completely formulated.

Assumptions related to proliferation criteria that were used in selecting the thorium fuel cycle described in this document are:

1. Unrestricted recycle of separated plutoniun is unacceptable.

2. Fissile uranium must be denatured with ${ }^{238} \mathrm{U}$.

3. Chemical processing plants must be located in secure areas.

4. Plutonium may be recycled through $\mathrm{Pu} / \mathrm{Th}$ fabrication plants to LWR reactors within these secure recycle areas.

5. Spent uranium fuel may be reprocessed within the secure recycle areas.

6. Uranium with a higher fissile content than the denaturing limit is available either in secure areas containing enrichment plants or in the secure recycle areas.

Reasons for, and consequences of, some of these assumed proliferation criteria are discussed in subsequent sections.

Uranium Denaturing and Re-enrichment

The amount of fissile material required to make any particular type of nuclear explosive device increases with the amount of ${ }^{238} \mathrm{U}$ assumed to be mixed with the fissile material. A proliferation resistance threshold for each fissile uranium isotope can be defined as the concentration of that isotope in $a^{2{ }^{38}} \mathrm{U}$ mixture at which and below which the explosive device is considered to be impractical 
or impossible without isotopic enrichment. The fissile isotope is then said to be denatured. Current estimates are that concentration limits of $20 \%$ for ${ }^{235} \mathrm{U}$ and $12 \%$ for ${ }^{23}{ }^{3} \mathrm{U}$ are acceptable. These estimates will be refined during the course of the TFCT Program. Plutonium cannot be denatured.

Typical thorium fuel compositions that meet this denaturing requirement are given in Table 1 . The denaturing limit for combinations of ${ }^{23}{ }^{3} \mathrm{U}$ and ${ }^{235} \mathrm{U}$ is assumed to be a linear combination of the limits for each isotope separately. Thus, the fraction of ${ }^{2}{ }^{8} \mathrm{U}$ required to denature the fissile uranium listed for the spent fuel in Table 1 is 0.135 compared to 0.177 actually present, and uranium recovered from spent fuel is inherently denatured.

Spent fuel does not have sufficient fissile content to be used directly in a uniform fuel loading. Either the thorium content must be reduced or equivalently the fissile content must be increased, for example, by blending with enriched uranium. The consequences of re-enriching the recycled fuel by blending with uranium of various enrichments are summarized in Table 2. It is assumed that $1 \mathrm{~kg}$ of spent fuel with the composition given in Table 1 is mixed with $\mathrm{x} \mathrm{kg}$ of ${ }^{235} \mathrm{U}$ and $\mathrm{k} \cdot \mathrm{x} \mathrm{kg}$ of ${ }^{238} \mathrm{U}$ where $\mathrm{x}$ is determined by requiring that the ratio of the sum of $\nu \Sigma_{f}$ to the sum of $\Sigma_{a}$ in the recycle fuel be equal to the ratio for fresh fuel, and $k$ is the ratio of ${ }^{238} \mathrm{U}$ to ${ }^{235} \mathrm{U}$. At the composition of spent fuel in an LWR, the following ratios are calculated.

$\begin{array}{lcc}\text { Isotope } & \sigma_{a}^{i} / \sigma_{a}^{t h} & \left(\nu \sigma_{f}\right)^{i} / \sigma_{a}^{t h} \\ { }^{2{ }^{32} \mathrm{Th}} & 1.0 & 0.07 \\ { }^{238} \mathrm{U} & 1.8 & 0.30 \\ 235 \mathrm{U} & 41 & 79 \\ 2{ }^{23} \mathrm{U} & 53 & 117\end{array}$

Significant parameters for comparing the use of various makeup concentrations are the increase in total ${ }^{238} \mathrm{U}$ in the reactor, at the expense of thorium, and the feed and separative work required to produce a fixed amount of fuel. Data for these parameters are derived from Table 2 and are given in Table 3. The results are also plotted in Figure 1. Clearly, the makeup uranium should contain the highest $235 \mathrm{U}$ level available. Since the ${ }^{235} \mathrm{U}$ in the makeup $U$ exceeds the denaturing limit, either the makeup $U$ can be securely shipped (if acceptable) to the recycle secure area or the recycle material can be shipped to the enrichment secure area for blending. The resulting blend is below the denaturing limit. 


\section{Disposition of Irradiated Thorium}

Irradiated thorium is radioactive and its use in fabrication plants will require remote operation. Since recycled uranium is also radioactive, it is proposed that irradiated thorium and uranium be recycled together. Fresh fuel can be fabricated using new thorium either in existing fabrication plants or in similar new plants. Recycled fuel will be fabricated in plants designed for remote operation. In this way, thorium mining requirements are reduced from the total lifetime throughput (if new thorium is always used) to the amount required to fill the pipeline (which is proportional to the number of reactors) plus enough to make up for minor burnup and processing losses.

\section{Disposition of Irradiated Plutonium}

Since fissile uranium must be denatured with ${ }^{238} \mathrm{U}$, plutonium will be produced during irradiation. As indicated in Table 1, plutonium comprises a little over $20 \%$ of the fissile isotopes produced during the irradiation and remaining after exposure to 29,000 MWD per metric ton. In a typical $1500 \mathrm{MT} /$ year chemical processing plant, the fissile plutonium throughput will be $10-15 \mathrm{~kg}$ per operating day. It is assumed that it will not be possible to design a thorium cycle chemical processing plant that will make it appreciably harder or more time-consuming to obtain plutonium, given control of a functioning plant, than is the case in a processing plant designed for a uranium fuel cycle. It is, therefore, assumed that the chemical processing plants for the denatured thorium cycle must be located in secure areas.

It has been calculated that, averaged over an assumed 30-year reactor 1 ife, $U$ feed requirements for a thorium cycle with storage of plutonium are about equal to those of the uranium cycle with recycle of uranium and plutonium and are $32 \%$ less than for the uranium stowaway cycle. Thus, a given amount of uranium feed will fuel $47 \%$ more reactors using the thorium ( $\mathrm{Pu}$ storage) cycle than using the uranium stowaway cycle. If plutonium is also recycled in the thorium cycle, the given amount of uranium will fue $110 \%$ more reactors than in the plutonium storage case. Thus, although plutonium recycle is not absolutely essential, it makes a significant contribution.

Since plutonium-bearing spent fuel must be processed in a secure area, it seems reasonable to burn it as $\mathrm{Pu} / \mathrm{Th}$ fuel in the secure area. Not only does it allow operation of additional reactors in the secure area without an increase in uranium resource requirements, but it also provides additional ${ }^{23} \mathrm{U}$ for recycle in dispersed reactors. Finally, it may be safer to burn the separated plutonium than to store it. 


\section{Fabrication Plants}

It is not the purpose of this section to discuss the design of fabrication plants but only their location in the fuel cycle. It is expected that plants designed to fabricate uranium fuel can be used to fabricate non-recycled thorium/uranium fuel. When fuel is recycled, plants designed for remote operation will be required. Two types of remotely operated fabrication plants are required although they are not necessarily completely independent. Plutonium/thorium fuel must be fabricated inside the secure area in which it is recovered and irradiated. Recycled uranium/thorium fabrication plants may be built anywhere since the fissile content is denatured. They may be combined with plutonium/thorium plants in secure areas if this is economically advantageous.

\section{Reactors}

Current light water reactors can be loaded with unrecycled thorium fuel. Receiving and handling facilities would have to be modified somewhat for recycled fuel. Reactors using plutonium/ thorium fuel would have to be located in secure areas. Full plutonium/thorium loads are probably feasible, but a supply of uranium/thorium fuel designed to be compatible with the plutonium/ thorium fuel should be available for use when there is insufficient plutonium for refueling a reactor.

As time proceeds, the use of HWR's loaded with thorium might become attractive and the fuel fabrication and reprocessing industry should be adaptable to the changes required.

\section{Chemical Processing Plants}

As described earlier, chemical processing is assumed to occur only in secure areas. The most important product would be the uranium stream which contains most of the fissile isotopes. Since the uranium is denatured, it does not matter, for proliferation resistance, whether it is coprocessed with some or all of the thorium or not. The uranium and/or thorium can be shipped to dispersed fabrication plant sites if desired.

The remainder of the fissile content of the spent fuel is plutonium. Since this is protected by keeping it in a secure area, it does not matter whether it is coprocessed with some of the thorium or not. 
Recycling of Spent Uranium Fuel

Although the unrestricted recycle of plutonium is unacceptable, it has been assumed that plutonium will be recycled within secure areas in the thorium cycle. If chemical processing plants are designed to handle spent uranium fuel, it is feasible from a technical and proliferation resistance point of view to reprocess the stockpile of spent uranium and to recycle the plutonium (mixed with thorium) within the secure area. The uranium would be sent to enrichment plants. The amount of excess processing capacity provided for this purpose would have to be chosen on the basis of an economic study. Since it is desirable not to require too large a fraction of reactor capacity within secure areas (for plutonium recycle), it is assumed that the rate of reprocessing spent uranium would remain small, and thus, that the spent uranium stockpile would last a number of years.

\section{Complete Fuel Cycle}

Figure 2 is a schematic diagram of a fuel cycle incorporating the concepts described in previous sections. The top row of blocks represents the current status of the industry. If a decision is made to convert to the thorium fuel cycle, existing uranium-based fuel fabrication plants and light water reactors would be converted.

Spent thorium-based fuel would be stored until chemical processing capacity becomes available. Chemical processing plants, located in secure areas, would recover spent uranium, would reenrich it with highly enriched uranium, and would ship it, together with recovered thorium, to fabrication plants designed for remote operation. Plutonium would also be recovered and transferred, together with recovered thorium, to fabrication plants within the secure area. Plutonium/thorium fuel would then be irradiated in reactors within the secure area. Recycled uranium/thorium would be used in these reactors in the absence of enough plutonium/thorium fuel. To the extent that excess chemical processing capacity is available, spent uranium based fuel would also be processed. Recovered plutonium would be used in co-located facilities and recovered uranium would be re-enriched in the enrichment plants.

\section{Fuel Alternatives and Choice of Reference Design}

A list of alternatives chosen to characterize the fuel in the thorium cycle is given in Table 4. Some of the implications of the various alternatives are discussed in this section. 
Most uranium-based reactor and assembly loadings are uniform except for variations in enrichment. There may be an advantage in the thorium cycle in introducing several types of fuel assemblies (core and blanket, for example) in a single reactor charge and in using assemblies with different types of fuel columns (seed and blanket design, for example). The primary implication of such mixed loadings for chemical processing is in the flexibility required of the head end (the shear design, for example). It appears to be worthwhile to provide this flexibility so that a range of LWR or HWR thorium fuel assembly designs can be reprocessed.

Candidate cladding materials are Zirealoy and stainless steel. Thorium is more difficult to dissolve than uranium, and the fluorine that is probably required as a catalyst will probably complex with and dissolve the Zircaloy, thus increasing the volumes of waste and complicating thorium dissolution. Stainless steel would be expected to dissolve to a lesser extent. However, if the thorium cycle is adopted partly because of its long range uranium resource savings, it is important to achieve a high conversion ratio during reactor operation and stainless steel absorbs many more neutrons than Zircaloy. A high conversion ratio would be reflected in a lower initial enrichment requirement with Zirealoy as opposed to stainless steel and thus as an immediate uranium savings. For this reason, Zirealoy was selected as the fuel cladding for the reference fuel cycle. Stainless steel cladding will be carried as a backup.

Possible fuel forms are oxides, carbides, nitrides, or metal alloys of uranium and thorium. Oxide is selected as a conservative choice because more irradiation experience with oxide fuel forms is available.

The product sent from the reprocessing plant to the fabrication plants could be oxide powder or some small refractory form such as microspheres obtained from the sol-gel process developed at Oak Ridge. Because the fissile uranium is denatured, little proliferation resistance advantage exists for coprocessing the uranium with thorium, and it is assumed that the uranium and thorium are recovered separately. Because ${ }^{233} \mathrm{U}$ wi.11 contain ${ }^{232} \mathrm{U}$ which is radioactive, it is assumed that recycled fuel will also use irradiated thorium rather than storing the thorium to allow decay. Oxide powder is the chosen form with microspheres, produced either at the processing plant or the fabrication plant, as a backup.

It is assumed that plutonium is recycled within the secure recycle area and that it will be recovered separately to minimize the capital investment required. The recovered plutonium will be mixed with irradiated thorium in the co-located fabrication plant. 
Additives to the fuel could be considered to increase reactor exposure limits or to make the irradiated fuel easier to dissolve. There is some evidence that MgO makes thorium easier to dissolve and the effect of its use on reactor performance and on dissolvability will be investigated. 
TABLE 1

Typical Fuel Compositions

\begin{tabular}{lclc} 
Isotope & \multicolumn{2}{l}{ Initial Fuel } & $\begin{array}{l}\text { Limit of Fresh } \\
\text { Recycie Comp. }\end{array}$ \\
Thesh & Spent & \\
${ }^{235} \mathrm{U}$ & 0.7785 & 0.7916 & 0.708 \\
${ }^{238} \mathrm{U}$ & 0.0443 & 0.0179 & - \\
${ }^{2{ }^{3} \mathrm{U}}$ & 0.1772 & 0.1769 & 0.257 \\
Fissile Pu & - & 0.0108 & 0.035
\end{tabular}.

a. At an assumed exposure of 29,000 MWD/MT.

b. Assuming ${ }^{23} \mathrm{U}$ available from thorium blanket irradiation. Most recycle material will be intermediate in composition between fresh fuel and this limit.

TABLE 2

Blending of $1 \mathrm{~kg}$ of Spent Fuel and Makeup $U$

\begin{tabular}{|c|c|c|c|c|c|}
\hline${ }^{235} U$ in Makeup $U$ & 0.2 & 0.3 & 0.5 & 0.9 & $\begin{array}{l}\text { Fresh } \\
\text { Fuelb }\end{array}$ \\
\hline $\mathrm{k}$ & 4 & 2.33 & 1.0 & 0.091 & - \\
\hline${ }^{23}{ }^{3} \mathrm{U}, \mathrm{g}$ & 10.8 & 10.8 & 10.8 & 10.8 & - \\
\hline${ }^{235} \mathrm{U}, \mathrm{g}$ & 28.2 & 26.8 & 26.0 & 25.5 & 44.3 \\
\hline${ }^{2{ }^{3}} \mathrm{U}, \mathrm{g}$ & 218.3 & 198.0 & 185.4 & 178.0 & 177.2 \\
\hline $23^{2} \mathrm{Th}, \mathrm{g}$ & 793.8 & 793.8 & 793.8 & 793.8 & 778.5 \\
\hline Total HM, g & 1051.2 & 1029.5 & 1016.0 & 1008.2 & 1000.0 \\
\hline Fresh fuel, $\mathrm{g}^{\alpha}$ & 0 & 21.7 & 35.2 & 43.0 & 51.2 \\
\hline Total ${ }^{233} \mathrm{U}, \mathrm{g}$ & 10.8 & 10.8 & 10.8 & 10.8 & - \\
\hline Total ${ }^{235} \mathrm{U}, \mathrm{g}$ & 28.2 & 27.8 & 27.5 & 27.4 & 46.6 \\
\hline Total ${ }^{238} \mathrm{U}, \mathrm{g}$ & 218.3 & 201.8 & 191.6 & 185.6 & 186.3 \\
\hline Total ${ }^{232} \mathrm{Th}, \mathrm{g}$ & 793.8 & 810.7 & 821.2 & 827.3 & 833.7 \\
\hline
\end{tabular}

a. The amount of heavy metal is largest when a makeup uranium value of 0.2 is used, and when fresh fuel is added to the other cases for the purpose of comparison.

$b$. Included for comparison with recycle fuel. 
TABLE 4

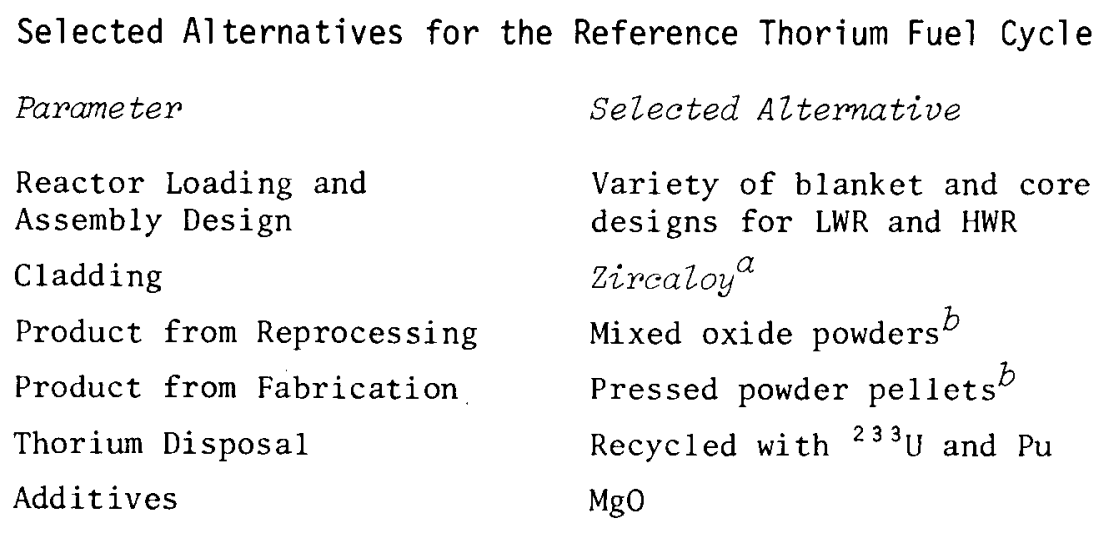

a. Stainless steel will be considered a backup candidate if chemical processing problems with Zircaloy are too great.

$b$. Oxide microspheres produced by the sol-gel process will be considered a backup. Microsphere production may be part of the fabrication plant.

TABLE 3

Comparison of Blended and Fresh Fuels per $1.051 \mathrm{~kg}$ Total Fuel

$\begin{array}{lccccc}{ }^{2{ }^{35}} \mathrm{U} \text { in Makeup } U & 0.2 & 0.3 & 0.5 & 0.9 & \begin{array}{c}\text { Fresh } \\ \text { Fuel }\end{array} \\ \text { Increase in }{ }^{2{ }^{8} \mathrm{U}, \%} & 17.2 & 8.4 & 2.9 & 0 & 0 \\ \text { Total U in Makeup, g } & 51.2 & 29.5 & 16.0 & 8.2 & - \\ \text { Total U in fresh fuel, } \mathrm{g}^{a} & 0 & 4.8 & 7.8 & 9.5 & 232.8 \\ \mathrm{U} \text { feed required, } \mathrm{kg}^{b} & 1.98 & 1.91 & 1.86 & 1.81 & 9.02 \\ \text { SW required, } \mathrm{kg} \mathrm{SWU}{ }^{b} & 2.34 & 2.32 & 2.31 & 2.30 & 10.65\end{array}$

a. A11 at $20 \%{ }^{235} \mathrm{U}$.

b. For comparison, the feed and $S W$ contents of $1.051 \mathrm{~kg}$ of uranium fuel $\left(3.3 \%{ }^{235} \mathrm{U}\right)$ are $6.38 \mathrm{~kg}$ and $5.22 \mathrm{~kg} \mathrm{SWU}$, respectively. 


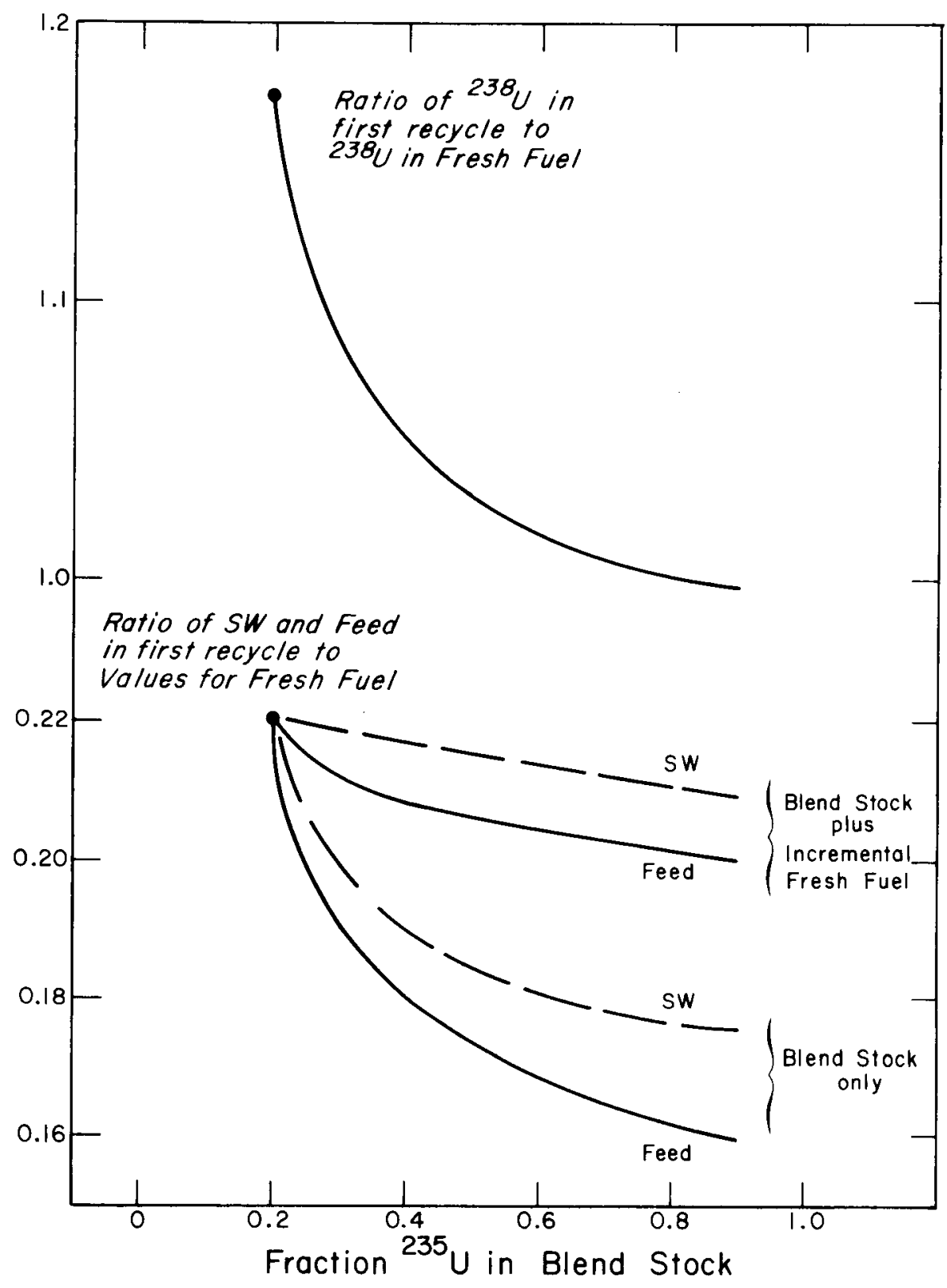

FIGURE 1. Effects of Blend Stock Enrichment 


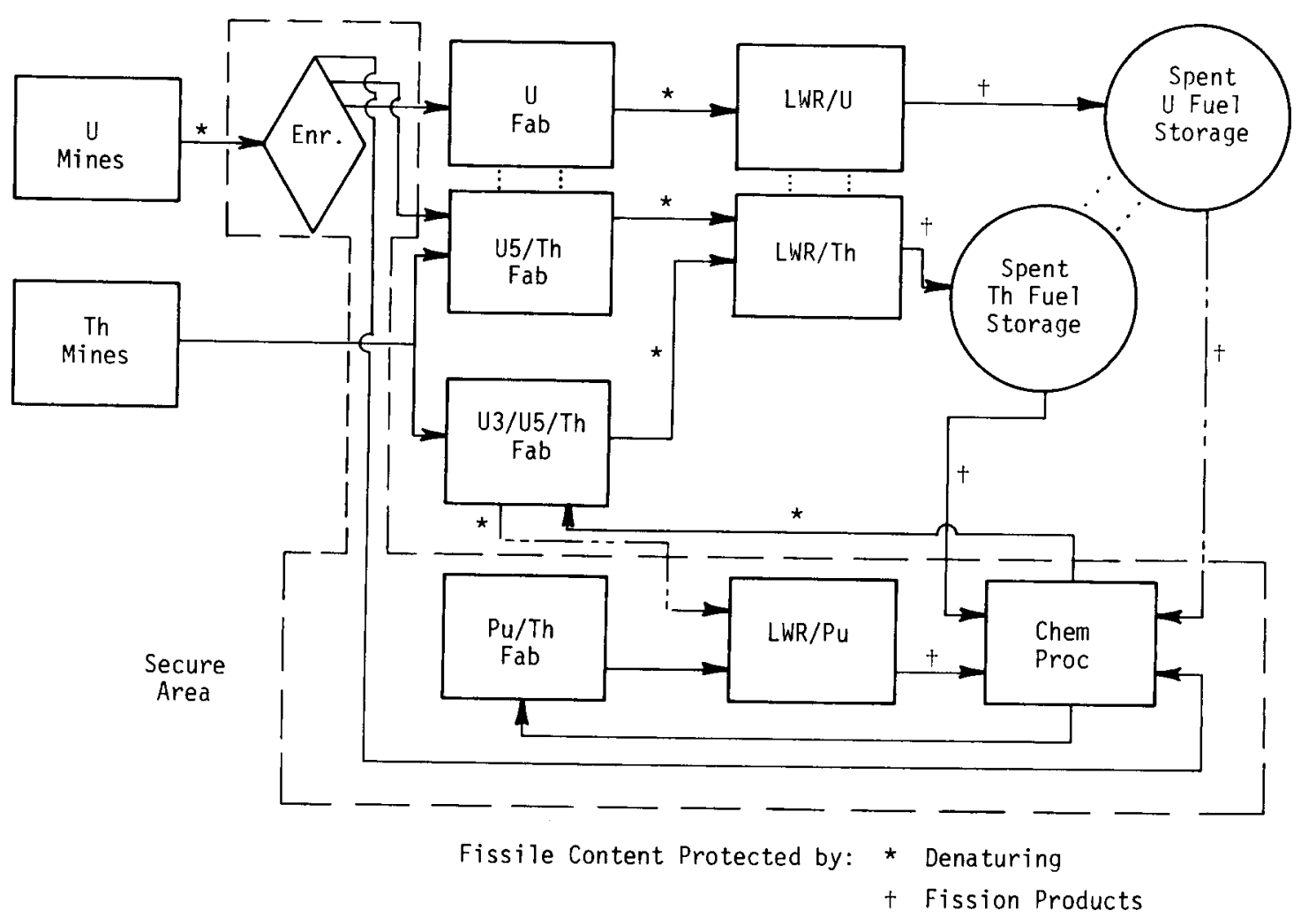

FIGURE 2. Proposed Thorium Fuel Cycle 